\title{
Large field emission current and density from robust carbon nanotube cathodes for continuous and pulsed electron sources
}

\author{
Jiangtao Chen, Bingjun Yang, Xiahui Liu, Juan Yang, Linfan Cui and Xingbin Yan*
}

\begin{abstract}
Highly adhesive cold cathodes with high field emission performance are fabricated by using a screen-printing method. The emission density of carbon nanotube (CNT) cold cathode reaches $207.0 \mathrm{~mA} \mathrm{~cm}$ at an electric field of 4.5 $\mathrm{V} \mu^{-1}$ under continuous driving mode, and high peak current emission of $315.8 \mathrm{~mA}$ corresponding to $4.5 \mathrm{~A} \mathrm{~cm}^{-2}$ at the electric field of $10.3 \mathrm{~V} \mathrm{\mu m}^{-1}$ under pulsed driving mode. The emission patterns of the cold cathodes are of excellent uniformity that was revealed by vivid luminescent patterns of phosphor coated transparent indium tin oxide (ITO) anode. The cold cathodes also exhibit highly stable emission under continuous and pulsed driving modes. The high adhesion of CNTs to molybdenum substrates results in robust cold cathodes and is responsible for the high field emission performance. This robust CNT emitter could meet the operating requirements of continuous and pulsed electron sources, and it provides promising applications in various vacuummicro/nanoelectronic devices.
\end{abstract}

Keywords: field emission, carbon nanotube, cold electron source

\section{INTRODUCTION}

Field emission electron source called cold cathode electron source is a promising candidate applied in many vacuum microelectronic devices. Field emission electron source has many merits, which is of rapid-response, miniaturization and without pre-heating before being used [1], compared to the thermal cathode. Moreover, complicated thermal-management system is unnecessary in cold electron devices but is required in solid-state devices working at low frequency and bandwidth regime [2,3]. Field emission electron source can achieve high current, high current density, low power consumption and work in a wide temperature range. In order to get the outstanding cold electron source which is an important issue for the development in the field emission display, field emission lamps, X-ray tubes, ultrahigh-frequency tubes and microwave power devices, the cathode material is a key to solve this issue. For practical field emission devices, the cathode materials are required to have low operating voltage, high emission current and density, uniformity, stability and long working life. Many kinds of nanostructured materials have been studied and potentially used as the electron emitters such as metal micro-tips, metal oxides, carbides and carbon nanostructures [4-10]. Among carbon nanostructures, carbon nanotubes (CNTs) possess stable chemical characteristic, excellent electrical and thermal conductivity, mechanical property and high aspect ratio, and therefore CNT-based emitters exhibit unique field emission performance.

CNT arrays (CNTAs) cold cathodes show low turn-on/threshold fields and high current emission density, and they are fabricated by thermal chemical vapor deposition (TCVD), plasma enhanced CVD (PECVD), and microwave PECVD (MWPECVD) techniques [11-13]. Screen-printing is another method to fabricate CNT emitters, by which the raw materials CNTs can be obtained independently. The screen-printed cathodes also display good field emission behaviors [14,15]. Although many investigations have been carried out and explored to develop the CNT-based field emission devices, some challenges remain and prevent the practical applications. For instance, the field emission current deterioration appears during long-term testing; acquiring high emission current needs high operating voltage but the emitters cannot endure high electric field. Furthermore, the theoretical prediction shows that CNTs can provide ultra-high field emission

Laboratory of Clean Energy Chemistry and Materials, State Key Laboratory of Solid Lubrication, Lanzhou Institute of Chemical Physics, Chinese Academy of Sciences, Lanzhou 730000, China

* Corresponding author (email: xbyan@licp.cas.cn) 
current and density, while high current and density are difficult to realize simultaneously in reality. The requirement of high power field emission devices is not only high current density but also high emission current. For X-ray generation, it requires a current density higher than 0.1-1 $\mathrm{A} \mathrm{cm}^{-2}$, and to get high-resolution X-ray image, the peak current should maintain tens of milliampere emission $[16,17]$. For applications in vacuum microwave devices, radar and communications, even higher emission current and density (in the order of $10^{-1} \mathrm{~A}$ corresponding to density of 2-10 $\mathrm{A} \mathrm{cm}^{-2}$ ) are required $[3,18,19]$. Table 1 summarizes the recent studies on field emission performance of CNT emitters. We can find that the high current density is achieved to several $\mathrm{A} \mathrm{cm}^{-2}$ but relates to lower current in the order of $10^{-4} \mathrm{~A}$ in direct current (DC) continuous mode. Similarly, highest current density of several A $\mathrm{cm}^{-2}$ reaches but the emission current is lower than $10^{-1}$ A under pulsed driving mode. Acquiring high current correspondingly high current density is important for the practical applications of CNT cathodes in high power devices. High emission current and density are closely associated with emitter uniformity, thermal dissipation, interface electrical contact and adhesion of CNT emitters. In order to get both of high emission current and density, one solution is to enhance the adhesion of CNT emitters to the substrates, which will bring low electrical contact at the interface and avoid local destroy of emission sites due to over-heating, and improve lifetimes. In this paper, we develop a highly adhesive CNT paste to fabricate the CNT cold cathodes with high field emission performance. The field emission behaviors, emission patterns and stability of the CNT emitters under DC continuous and pulsed driving modes are investigated in detail.

\section{EXPERIMENTAL SECTION}

\section{Preparation of CNT emitters}

The CNT cold cathodes on molybdenum (Mo) substrates were prepared by the screen-printing method. In this work, we employed a ball-milling method to prepare highly homogeneous pastes for screen-printing cold cathodes. The processes including ball milling for preparing pastes, screen-printing cathodes and post-thermal treatments were optimized. Here, single-walled CNTs (SWCNTs, purchased from Nanjing XFNANO Materials TECH Co., Ltd) without further treatment were used as electron emitters. For good dispersion, $0.3 \mathrm{~g}$ CNTs and $15 \mathrm{~g}$ terpilenol were ball-milled using $\mathrm{ZrC}$ balls (carried on Pulverisette 7, FRITSCH) for $50 \mathrm{~min}$, and then $0.8 \mathrm{~g}$ ethyl cellulose as organic binder was added and ball-milled again for $100 \mathrm{~min}$ to obtain pristine CNT paste. For improving the adhesion of the cathode to the substrate, $0.3 \mathrm{~g}$ Ni nanopowders were mixed with terpilenol in advance, and the paste with conductive nanoparticles were obtained. In order to further

Table 1 Summary of field emission characteristics of CNT cathodes

\begin{tabular}{|c|c|c|c|c|c|}
\hline Cold cathode & Method & $I_{\max }(\mathrm{mA})$ & $\begin{array}{c}J_{\max } \\
\left(\mathrm{A} \mathrm{cm}^{-2} @ \mathrm{~V} \mu \mathrm{m}^{-1}\right)\end{array}$ & Driving mode & Ref. \\
\hline CNTAs & PECVD & 0.31 & 0.0025@5 & Continuous & {$[12]$} \\
\hline CNTs & MWPECVD & 0.30 & $6.0 @ 7.4$ & Continuous & {$[13]$} \\
\hline CNTs & Screen printing & 102 & $0.16 @ 4.1$ & Continuous & [14] \\
\hline CNTs & Screen printing & 4 & $0.15 @ 2.5$ & Continuous & {$[15]$} \\
\hline CNTAs & MWPECVD & l & $0.015 @ 1.6$ & Continuous & {$[20]$} \\
\hline CNTs & Screen printing & l & $0.040 @ 3.3$ & Continuous & {$[21]$} \\
\hline Graphene/CNTs & TCVD/PECVD & 4.0 & $0.085 @ 2.8$ & Continuous & {$[22]$} \\
\hline CNTAs & PECVD & l & $0.070 @ 7.5$ & Continuous & {$[23]$} \\
\hline CNTs & Screen printing & 0.22 & $11.2 @ 18.5$ & Continuous & {$[24]$} \\
\hline CNTs & TCVD & 2.7 & $0.27 @ 5.2$ & Pulsed & {$[11]$} \\
\hline CNTs & Screen printing & 88.0 & $11.2 @ 12.8$ & Pulsed & {$[17]$} \\
\hline CNTs & PECVD & 10.0 & 10.0@14 & Pulsed & {$[25]$} \\
\hline CNTs & TCVD & 16.0 & 0.80@8.0 & Pulsed & {$[26]$} \\
\hline h-BN/CNTAs & TCVD & 3.7 & $0.093 @ 6.5$ & Pulsed & {$[27]$} \\
\hline \multirow{2}{*}{ CNTs } & \multirow{2}{*}{ Screen printing } & 5.0 & $0.207 @ 4.5$ & Continuous & This work \\
\hline & & 315.8 & 4.5@10.3 & Pulsed & This work \\
\hline
\end{tabular}


improve the adhesion, highly adhesive CNT paste was prepared by adding $0.5 \mathrm{ml}$ high temperature paint. For briefness, the abbreviations PP, CP and HAP were used to represent the pristine paste, conductive nanoparticles added paste, and highly adhesive paste, respectively. The cathodes with diameters of 1.7 and $3.0 \mathrm{~mm}$ were screen-printed using patterned screen and pastes mentioned above. The as-printed cathodes were thermal-treated at $200^{\circ} \mathrm{C}$ in air for $60 \mathrm{~min}$ and subsequently annealed at $700^{\circ} \mathrm{C}$ in vacuum with base-pressure of $10^{-4} \mathrm{~Pa}$ for $60 \mathrm{~min}$. Finally, the CNT cathodes were mechanically activated by conventional adhesive tape method using $3 \mathrm{M}$ scotch tape with no trace left. For convenience, the CNT cathodes derived from PP, CP and HAP were denoted as CPP, CCP and CHAP, respectively.

\section{Characterizations and field emission measurements}

Raman spectra for CNT emitters were collected by using a micro-Raman spectroscopy (JY-HR800, the excitation wavelength of $532 \mathrm{~nm}$ ). Transmission electron microscopy (TEM, TECNAI G2 TF20) with an accelerating voltage of $200 \mathrm{kV}$ and field emission scanning electron microscopy (FESEM, JSM 6701F) were used to observe the structure of CNTs and surface morphologies of the cathode samples. The field emission behaviors of the emitters were performed in a diode-type geometry inside a vacuum chamber with high vacuum conditions of $5.0 \times 10^{-6} \mathrm{~Pa}$. During the measurements, the distance between the cathode and anode remained $300 \mu \mathrm{m}$. The current-voltage $(I-V)$ characteristics of continuous driving mode were measured by LabVIEW programming through a Keithley 248 power source with a computer-controlled data-acquisition card. The $I-V$ characteristics were also studied under pulsed driving mode. The pulse width was kept at $10 \mu$ s with different frequencies of 50, 200 and $400 \mathrm{~Hz}$. The field emission data under pulsed driving mode were collected by reading the voltage-drop of series load resistance from high-precision digital oscilloscope (RIGOL DS2072A). The schematic of experimental set-up for pulsed mode testing is shown in Fig. S1 (Supplementary information). Furthermore, by applying the voltage to indium tin oxide (ITO) anode coated with the phosphor, the field emission patterns of cathodes were recorded by a digital camera. Furthermore, in order to study the adhesion property, the simple and facile tests were carried out on the CPP, CCP and CHAP. In these tests, the $3 \mathrm{M}$ scotch tape was clung on the cathode surface, which lasted for 3-5 min. Then the adhesive tape was stripped off from the surface before taking the direct observation of the adhesion performance of the CNTs to the substrates.

\section{RESULTS AND DISCUSSION}

The purchased CNTs were examined by TEM and SEM, and the images are shown in Figs S2, S3. From the TEM images, the bundles of CNTs can be observed, but the diameter of an individual CNT cannot be estimated. The length of CNTs is with several micrometres (as shown in Fig. S3). Fig. 1a displays the digital photograph of CHAP with $3 \mathrm{~mm}$ in diameter, and the cathode is of uniformity. Fig. $1 \mathrm{~b}$ shows the Raman spectrum of the CHAP. The predominant peak located at $1594 \mathrm{~cm}^{-1}$ is corresponding to $\mathrm{G}$ band (C-C sp bonds) and the weak peak certred at $1345 \mathrm{~cm}^{-1}$ is indexed to $\mathrm{D}$ band ( $\mathrm{C}-\mathrm{C} \mathrm{sp}^{3}$ bonds) [28]. The Raman spectrum presents the typical charactertics of the SWCNTs with high crystallization nature. Fig. 1c, d display the FESEM images of the CPP and CHAP, respectively. As shown in Fig. 1c, there are only CNTs observed in CPP. In Fig. 1d, it can be seen that the additives are distributed among the CNTs of CHAP.

In order to investigate the adhesion of the cathodes to Mo substrates, the adhesion tests were carried out and the photographs of the samples after testing are shown in Fig. 2. Observed from Fig. 2a, the CNTs of CPP are drastically peeled off from the Mo substrate, indicating weak adhesion of CNTs. As expected, there is a remarkble reinforcement in adhesion property for the CCP and especially CHAP, as shown in Fig. 2b, c respectively. The good adhesion will reinforce electrical contact of CNTs to the substrate and improve the field emisison property of the CNT cathodes.

For further verification of the adhesion effect, the field emission performances of different cathodes were investigated. Field emission performances of CPP and CCP under pulsed driving mode $(200 \mathrm{~Hz}, 10 \mu \mathrm{s})$ are displayed in Fig. 3. The field emission current of pure CNTs (CPP) reaches $151.6 \mathrm{~mA}$ corrsponding to $2.2 \mathrm{~A} \mathrm{~cm}^{-2}$ at the electric field of $7.5 \mathrm{~V} \mu \mathrm{m}^{-1}$. For CCP, the field emission current reaches $252.6 \mathrm{~mA}$ corrsponding to $3.6 \mathrm{~A} \mathrm{~cm}^{-2}$ at the electric field of $8.0 \mathrm{~V} \mu \mathrm{m}^{-1}$. During field emission testing, the arcing took place when elevating the electric field furthur for acquiring higher current emission, and this process destroyed the cathodes (CPP). The arcing did not appear on CCP, and the CCP obtained higher current emission under higher electric field. The adding of the conductive nanoparticles enhances the field emission of the cathodes and tolerance to high electric field, which is derived from improvement in adhesion of CNTs to the substrate.

Fig. 4 shows the field emission performance of the sample CHAP. Firstly, we examined the field emission of CHAP under continuous driving mode. Due to limitation of the power supply of voltage source, the maximum current was 

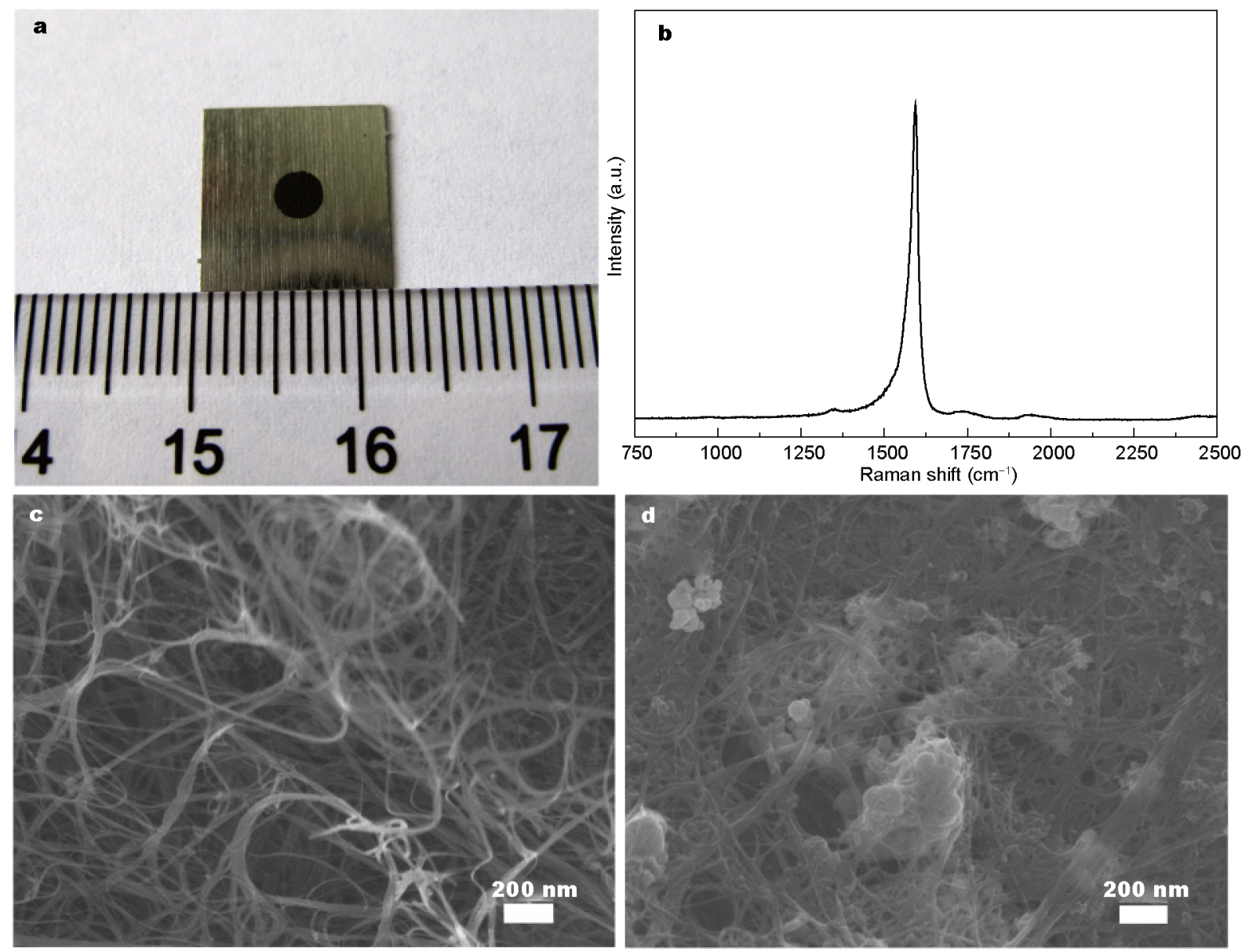

Figure 1 The photograph (a) and Raman spectrum (b) of CHAP; the surface morphologies of (c) CPP and (d) CHAP.
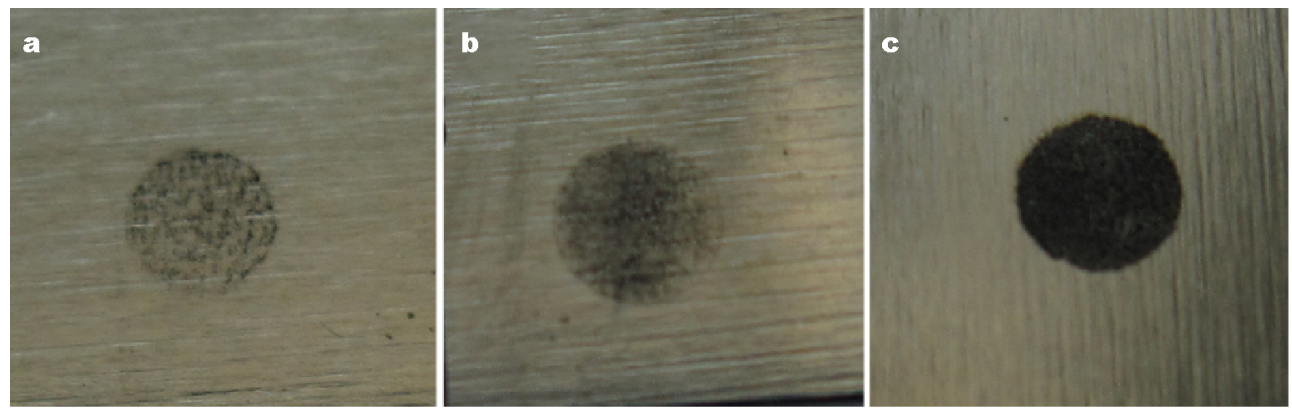

Figure 2 The photographs of CNT emitters (3 mm in diameter) after adhesion test by using 3M scotch tape: (a) CPP, (b) CCP and (c) CHAP.

recorded within $5.0 \mathrm{~mA}$ for continuous driving mode. As seen from Fig. 4a, the sample with diameter of $1.7 \mathrm{~mm}$ can emit the current of $\sim 5.0 \mathrm{~mA}$ corresponding to large density of $207.0 \mathrm{~mA} \mathrm{~cm}^{-2}$ at the electric field of $4.5 \mathrm{~V} \mathrm{\mu m}^{-1}$. The turn on and threshold fields are 2.4 and $2.7 \mathrm{~V} \mathrm{\mu m}^{-1}$ respectively for extracting the current density of 0.1 and $1 \mathrm{~mA} \mathrm{~cm}^{-2}$. The field emission characteristics are further analyzed with the
Fowler-Nordheim theory described by

$$
J=A \phi^{-1} \beta^{2} E^{2} \exp \left(-\frac{B \phi^{3 / 2}}{\beta E}\right),
$$

where $A$ and $B$ are the temperature-independent constants $\left(A=1.54 \times 10^{-6} \mathrm{~A} \mathrm{eV} \mathrm{V}^{-2}\right.$ and $\left.B=6.83 \times 10^{9} \mathrm{eV}^{-3 / 2} \mathrm{~V} \mathrm{~m}^{-1}\right), \phi$ is the work function and here assumed to be $5 \mathrm{eV}$ for CNTs 


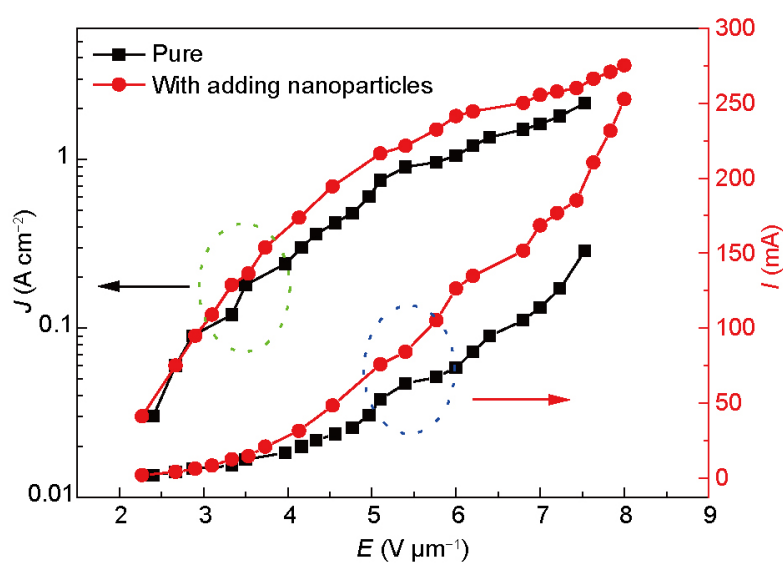

Figure 3 Maximum field emission current of CPP and CCP under pulsed driving mode $(200 \mathrm{~Hz}, 10 \mu \mathrm{s})$.

$[29,30], \beta$ is the field enhancement factor, $J$ and $E$ are the emission current density and applied electric field, respectively. The plot of $\ln \left(j / E^{2}\right)$ versus $1 / E$ is called the F-N plot
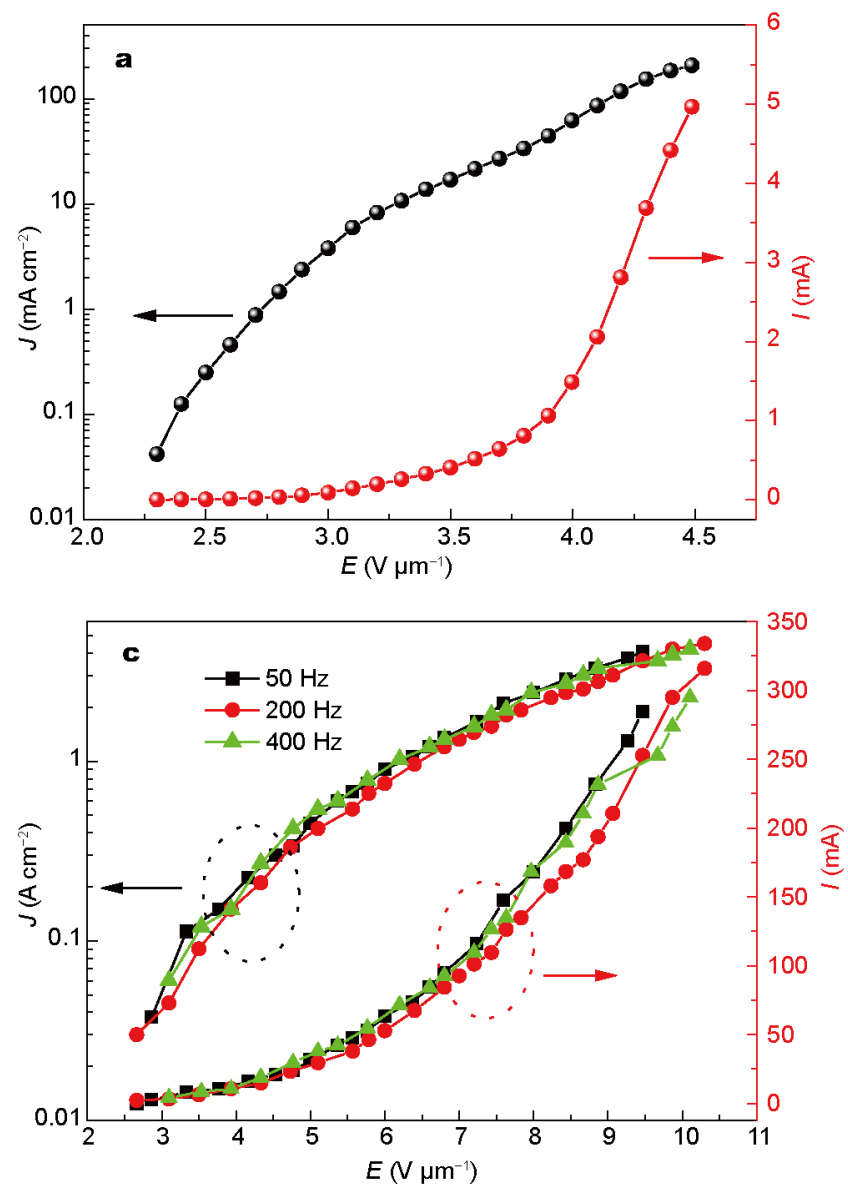

and $\beta$ is given by the following expression

$$
\beta=-\frac{B \phi^{3 / 2}}{\kappa_{\text {slope }}} .
$$

Based on the $\kappa_{\text {slope }}$ from the F-N plot, $\beta$ can be estimated. Fig. $4 \mathrm{~b}$ shows the typical F-N plot and presents a nearly straight line, which indicates that the electrons are from field emission process controlled by quantum mechanical tunneling. The $\kappa_{\text {slope }}$ is calculated to be -31.42 . The $\beta$ can be calculated to be 2,430. For comparison, the field emission of CHAP with diameter of $3 \mathrm{~mm}$ was investigated by continuous driving mode, as shown in Fig. S4. The current density reaches $71 \mathrm{~mA} \mathrm{~cm}^{-2}$ with the current of $4.9 \mathrm{~mA}$ (the power source supplies the max current of $5.0 \mathrm{~mA}$ ) at the electric field of $3.8 \mathrm{~V} \mathrm{\mu m}^{-1}$. From the F-N plot (the inset of Fig. S4), the $\beta$ can be calculated to be 4,314 . Fig. $4 c$ displays the pulsed field emission behaviors of the CHAP with $3 \mathrm{~mm}$ in diameter. The pulse width is fixed at $10 \mu$ s with different frenquencies of 50, 200 and $400 \mathrm{~Hz}$. The emission current of CHAP under $50 \mathrm{~Hz}$ reaches $284.2 \mathrm{~mA}$ (corresponding to
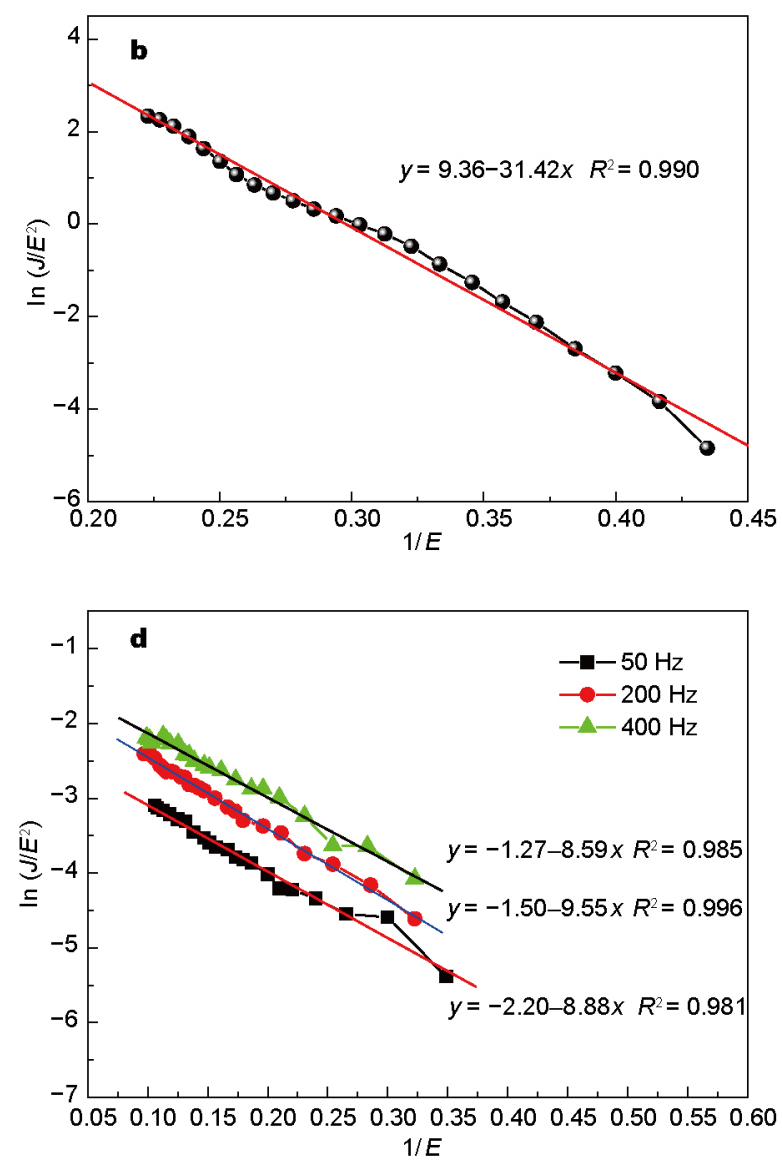

Figure 4 Field emission behaviors of CHAP. Continuous driving mode: (a) $J(I)-E$ curves and (b) F-N plot; pulsed driving mode in various frequencies: (c) $J(I)-E$ curves and (d) F-N plots. For clear observation, the $Y$-axis for 200 and $400 \mathrm{~Hz}$ F-N plots moves up by 0.75 and 1.5 , respectively. 
the current density of $4.1 \mathrm{~A} \mathrm{~cm}^{-2}$ ) at the electric field of $9.5 \mathrm{~V} \mathrm{\mu m}^{-1}$, and maximum current of $294.7 \mathrm{~mA}$ (corresponding to the current density of $4.2 \mathrm{~A} \mathrm{~cm}^{-2}$ ) is achieved at the electric field of $10.1 \mathrm{~V} \mathrm{\mu m}^{-1}$ under $400 \mathrm{~Hz}$. Furthermore, under $200 \mathrm{~Hz}$ driving mode, the highest emission current of $315.8 \mathrm{~mA}$ (corresponding to the current density of $4.5 \mathrm{~A} \mathrm{~cm}^{-2}$ ) is obtained at the electric field of 10.3 $\mathrm{V} \mu \mathrm{m}^{-1}$. No remarkble change of field emission behaviors is observed under different frenquencies with pulse width of $10 \mu \mathrm{s}$. CHAPs have further enhanced the field emission performance including high emission current and density, and endurance of high electric field. The best field emission characterictic is resulted from the strong adhesion of CNTs to the substrate, which is reflected by the adhesion tests shown in Fig. 2. The strong adhesion between CNTs and Mo substrate brings good mechanical and electrical contacts at the interface, and consequently the highly robust CNT cathodes were developed. Table 1 shows the comparison of field emission characteristics of CNT-based emitters in present study with those reported previously. The above results clearly demonstrate that the CNT cathodes developed in our work possess high emission current and high current density simultaneously, meeting the operating requirements of high power electronic devices. Fig. $4 \mathrm{~d}$ shows the F-N plots of field emission from CHAP under different frequencies. A nearly straight line indicates that the electron emission is field emission process. The field enhancement factor $\beta$ are calculated to be $8,599,7,996$ and 8,890 for CHAP driving at 50, 200 and $400 \mathrm{~Hz}$ respectively. There is no remarkable difference in $\beta$ when driven by pulsed mode. However, $\beta$ is higher than that of the cathode driven under continuous mode. Generally, $\beta$ is strongly dependent on the geometrical shape of emitters. The geometry (such as aspect ratio, surface morphology and roughness, inter-electrode distance) and work function are identical for the cathodes tested here. The driving modes will affect the vacuum space charge (accumulation of charge) and local states of the emitter surface (gas adsorption and desorption process), leading to the change in screening effect and effective work function. In other words, weakening of screening effect derived from space charge and decreasing of effective work function resulted from change of local states under pulsed driving mode contribute to the larger field enhancement factor compared to that of cathode driving at continuous mode.

The field emission stability of the cathode is shown in Fig. 5. The field emission stability was monitored for 3600 $s$ at different current densities and driving modes. Under continuous mode, the stability with initial current densities

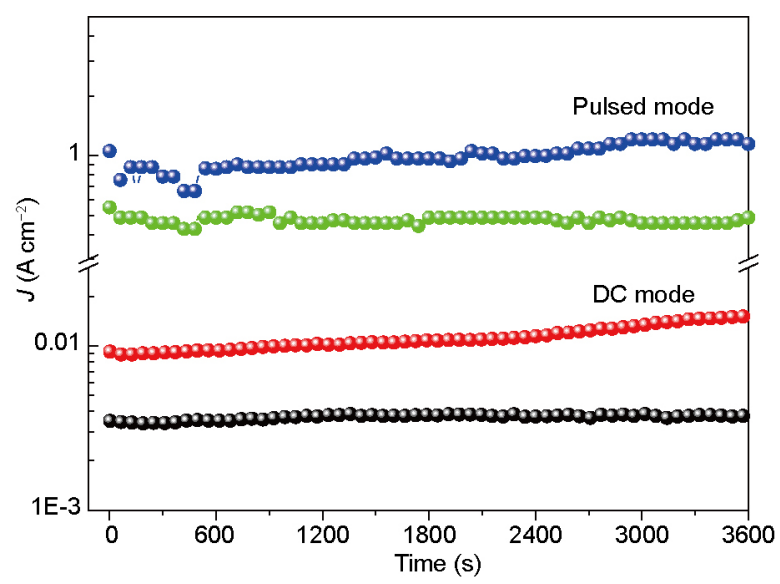

Figure 5 Emission stability measurements of CHAP in continuous and pulsed $(200 \mathrm{~Hz}, 10 \mu \mathrm{s})$ driving modes.

of 3.5 (black curve) and 9.2 (red curve) $\mathrm{mA} \mathrm{cm}^{-2}$ at constant and continuous electric fields are shown in Fig. 5. It is indicated that the CHAP displays good emission stability without evident degradation. Similarly, CHAP also displays good emission stability with initial current densities of 0.55 (green curve) and 1.05 (blue curve) $\mathrm{A} \mathrm{cm}^{-2}$ at pulsed electric fields condition of $200 \mathrm{~Hz}$ and $10 \mu$ s. Due to self-heating process of the emitter [31-33] particulary at large current density, a slight increase in emission density can be found during the test. The long-time stability of the cathode at initial current density of $1.3 \mathrm{~mA} \mathrm{~cm}^{-2}$ under continuous driving mode is shown in Fig. S5, and there is no obvious deterioration of emission performance during 45 $\mathrm{h}$ testing period.

Figs 6, 7 exhibit the luminescence photographs by utilizing phosphor coated transparent ITO glass as anode and the electron emission patterns can be observed clearly when driven by different modes. As shown in Fig. 6, bright luminescence can be observed at continuous driving mode, and a spread of the electrons is found according to the size
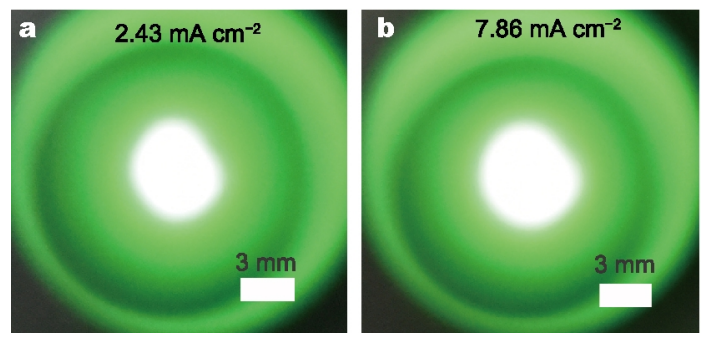

Figure 6 Luminescence photographs show the emission patterns from CHAP ( $3 \mathrm{~mm}$ in diameter) under various current emission densities in continuous driving modes $(\mathrm{a}-\mathrm{b})$. 

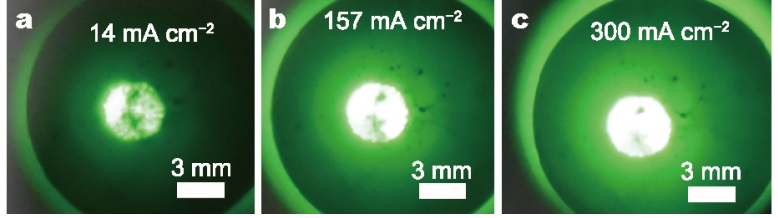

Figure 7 Luminescence photographs show the emission patterns from CHAP (3 mm in diameter) under various current densities in pulsed driving mode $(\mathrm{a}-\mathrm{c}) 200 \mathrm{~Hz}, 10 \mu \mathrm{s}$.

of the spot. Fig. 7 displays the emission patterns from CHAP under a series of current emission densities in pulsed driving mode at $200 \mathrm{~Hz}$ and $10 \mu$ s. Attributed to edge effect, the sites on the edge is prior to emit electrons.

\section{CONCLUSIONS}

In conclusion, this work demonstrates the preparation of highly robust CNT cathodes on Mo substrate and their corresponding field emission performance under continuous and pulsed operation modes. The screen-printed cathodes are robust, which display high adhesion to the substrate and endurance to the high electric field. Under continuous driving mode, a high current density of $207.0 \mathrm{~mA} \mathrm{~cm}^{-2}$ is achieved at electric field of $4.5 \mathrm{~V} \mu \mathrm{m}^{-1}$. Furthermore, a high peak current of $315.8 \mathrm{~mA}$ corresponding to $4.5 \mathrm{~A}$ $\mathrm{cm}^{-2}$ at electric field of $10.3 \mathrm{~V} \mathrm{\mu \textrm {m } ^ { - 1 }}$ under pulsed driving mode is obtained. The cold electron emitters show high performance of field electron emission under continuous and pulsed driving modes, providing promising applications in various vacuum-micro/nanoelectronic devices.

\section{Received 24 December 2016; accepted 24 February 2017;} published online 13 March 2017

1 Whaley DR, Duggal R, Armstrong CM, et al. $100 \mathrm{~W}$ operation of a cold cathode TWT. IEEE Trans Electron Devices, 2009, 56: 896-905

2 Verma P, Gautam S, Pal S, et al. Carbon nanotube-based cold cathode for high power microwave vacuum electronic devices: a potential field emitter. Defence Sci J, 2008, 58: 650-654

3 Milne WI, Teo KBK, Minoux E, et al. Aligned carbon nanotubes/fibers for applications in vacuum microwave amplifiers. J Vac Sci Technol B, 2006, 24: 345-348

4 Xu NS, Huq SE. Novel cold cathode materials and applications. Mater Sci Eng-R-Rep, 2005, 48: 47-189

5 Yanagisawa $\mathrm{H}$, Hafner $\mathrm{C}$, Doná $\mathrm{P}$, et al. Laser-induced field emission from a tungsten tip: optical control of emission sites and the emission process. Phys Rev B, 2010, 81: 115429

6 Sankaran KJ, Afsal M, Lou SC, et al. Electron field emission enhancement of vertically aligned ultrananocrystalline diamond-coated $\mathrm{ZnO}$ core-shell heterostructured nanorods. Small, 2014, 10: 179-185

7 Chen S, Shang M, Gao F, et al. Extremely stable current emission of P-doped SiC flexible field emitters. Adv Sci, 2016, 3: 1500256

8 Chen J, Cui L, Sun D, et al. Enhanced field emission properties from aligned graphenes fabricated on micro-hole patterned stainless steel. Appl Phys Lett, 2014, 105: 213111

9 Chen J, Yang B, Liu X, et al. Field electron emission from pencildrawn cold cathodes. Appl Phys Lett, 2016, 108: 193112

10 Sridhar S, Tiwary C, Vinod S, et al. Field emission with ultralow turn on voltage from metal decorated carbon nanotubes. ACS Nano, 2014, 8: 7763-7770

11 Lahiri I, Wong J, Zhou Z, et al. Ultra-high current density carbon nanotube field emitter structure on three-dimensional microchanneled copper. Appl Phys Lett, 2012, 101: 063110

12 Gautier LA, Le Borgne V, El Khakani MA. Field emission properties of graphenated multi-wall carbon nanotubes grown by plasma enhanced chemical vapour deposition. Carbon, 2016, 98: 259-266

13 Chen Z, den Engelsen D, Bachmann PK, et al. High emission current density microwave-plasma-grown carbon nanotube arrays by postdepositional radio-frequency oxygen plasma treatment. Appl Phys Lett, 2005, 87: 243104

14 Park SA, Song EH, Kang BH, et al. Carbon nanotube field emitters on KOVAR substrate modified by random pattern. J Nanopart Res, 2015, 17: 318

15 Kim JW, Jeong JW, Kang JT, et al. Great improvement in adhesion and uniformity of carbon nanotube field emitters through reactive nanometer-scale SiC fillers. Carbon, 2015, 82: 245-253

16 Calderón-Colón X, Geng H, Gao B, et al. A carbon nanotube field emission cathode with high current density and long-term stability. Nanotechnology, 2009, 20: 325707

17 Lei W, Zhu Z, Liu C, et al. High-current field-emission of carbon nanotubes and its application as a fast-imaging $\mathrm{X}$-ray source. Carbon, 2015, 94: 687-693

18 Makishima H, Miyano S, Imura H, et al. Design and performance of traveling-wave tubes using field emitter array cathodes. Appl Surface Sci, 1999, 146: 230-233

19 Jensen KL. Field emitter arrays for plasma and microwave source applications. Phys Plasmas, 1999, 6: 2241-2253

20 Kar R, Sarkar SG, Basak CB, et al. Effect of substrate heating and microwave attenuation on the catalyst free growth and field emission of carbon nanotubes. Carbon, 2015, 94: 256-265

21 Cha SI, Kim KT, Arshad SN, et al. Field-emission behavior of a carbon-nanotube-implanted Co nanocomposite fabricated from pearl-necklace-structured carbon nanotube/Co powders. Adv Mater, 2006, 18: 553-558

22 Deng JH, Cheng L, Wang FJ, et al. High current density and longtime stable field electron transfer from large-area densely arrayed graphene nanosheet-carbon nanotube hybrids. ACS Appl Mater Interfaces, 2014, 6: 21558-21566

23 Cui L, Chen J, Yang B, et al. High current emission from patterned aligned carbon nanotubes fabricated by plasma-enhanced chemical vapor deposition. Nanoscale Res Lett, 2015, 10: 483

24 Choi YC, Kang JT, Park S, et al. Preparation of a miniature carbon nanotube paste emitter for very high resolution X-ray imaging. Carbon, 2016, 100: 302-308

25 Li C, Zhang Y, Cole MT, et al. Hot electron field emission via individually transistor-ballasted carbon nanotube arrays. ACS Nano, 2012, 6: 3236-3242

26 Zhang Y, Deng S, Du J, et al. Effects of pulsewidth and area of carbon nanotube films on their pulsed field emission characteristics. IEEE Trans Electron Devices, 2013, 60: 2677-2681

27 Yang X, Li Z, He F, et al. Enhanced field emission from a carbon nanotube array coated with a hexagonal boron nitride thin film. Small, 2015, 11: 3710-3716

28 Pernía Leal M, Assali M, Cid JJ, et al. Synthesis of 1D-glyconanomaterials by a hybrid noncovalent-covalent functionalization of 
single wall carbon nanotubes: a study of their selective interactions with lectins and with live cells. Nanoscale, 2015, 7: 19259-19272

Di Y, Xiao M, Zhang X, et al. Large and stable emission current from synthesized carbon nanotube/fiber network. J Appl Phys, 2014, 115: 064305

30 Zanin H, May PW, Hamanaka MHMO, et al. Field emission from hybrid diamond-like carbon and carbon nanotube composite structures. ACS Appl Mater Interfaces, 2013, 5: 12238-12243

31 Li J, Chen J, Luo B, et al. The improvement of the field emission properties from graphene films: Ti transition layer and annealing process. AIP Adv, 2012, 2: 022101

32 Vincent P, Purcell ST, Journet C, et al. Modelization of resistive heating of carbon nanotubes during field emission. Phys Rev B, 2002, 66: 075406

33 Purcell ST, Vincent P, Journet C, et al. Hot nanotubes: stable heat- ing of individual multiwall carbon nanotubes to $2000 \mathrm{~K}$ induced by the field-emission current. Phys Rev Lett, 2002, 88: 105502

Acknowledgments This work was supported by the National Natural Science Foundation of China (51002161) and One-Three-Five Strategic Planning of Chinese Academy of Sciences.

Author contributions All authors contributed to the discussion and preparation of the manuscript. The final version of the manuscript was approved by all authors.

Conflict of interest The authors declare that they have no conflict of interest.

Supplementary information The schematic of pulsed field emission testing system, structure of CNTs, field emission and long-time stability curves of CHAP are available in the online version of this paper

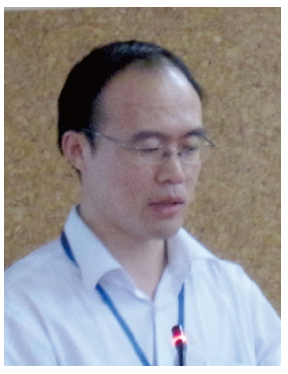

Jiangtao Chen received his $\mathrm{PhD}$ degree in condensed matter physics from the School of Physical Science \& Technology, Lanzhou University in 2009. He is now an associate professor at Lanzhou Institute of Chemical Physics (LICP), Chinese Academy of Sciences (CAS). His research interest focuses on the preparation and application of carbon nanomaterials (carbon nanotubes, graphene and carbon quantum dots) for field emission and optoelectronic devices.

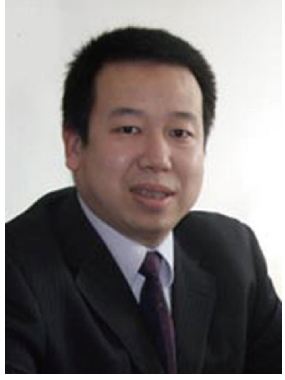

Xingbin Yan received his PhD degree in physical chemistry from LICP, CAS in 2005. Then he worked at Nanyang Technological University as a research fellow and the University of Lyon as a postdoctoral researcher. He is now the director of the Laboratory of Clean Energy Chemistry and Materials, LICP, CAS. His research group works on energy storage devices including supercapacitors and rechargeable batteries. For details, please see the lab website: www.licp.cas.cn/yxbz.

\section{连续/脉冲电子源用大电流高密度场发射碳纳米管冷阴极}

陈江涛, 杨兵军, 刘夏辉, 杨娟, 崔琳凡, 阎兴斌*

摘要 本文采用丝网印刷技术制备了具有高粘接性能的碳纳米管冷阴极. 该碳纳米管冷阴极在直流连续及脉冲场下均具有优异的场发射 性能, 同时具有高发射电流密度与发射总电流, 可以满足高功率器件对冷阴极电子源的使用需求. 在直流连续场下, 该冷阴极的电流发射密

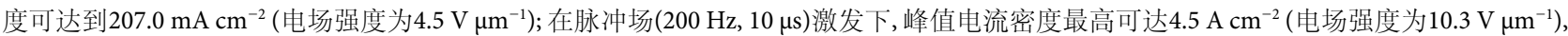
同时具有高的峰值发射电流 (315.8 mA). 为观察阴极发射均匀性, 采用苂光板为阳极进行实时监测, 发现此印刷阴极发射较均一; 稳定性测 试表明该阴极在连续及脉冲场下均具有良好的发射稳定性. 该冷阴极同时具有高电流密度及高发射电流, 可以满足高功率真空电子器件 的使用要求, 在真空微纳电子器件中显示出巨大的应用前景. 